\title{
Clinical Considerations in Physician-Assisted Death for Probable Alzheimer's Disease: Decision-Making Capacity, Anosognosia, and Suffering
}

\author{
Jaime D. Mondragón ${ }^{a, b}$ Latife Salame ${ }^{c, d} \quad$ Arnoldo Kraus $^{c, d}$ \\ Peter Paul De Deyn ${ }^{a}$, b, e \\ a Department of Neurology, University Medical Center Groningen, University of Groningen, \\ Groningen, The Netherlands; ${ }^{b}$ Alzheimer Research Center Groningen, University Medical \\ Center Groningen, University of Groningen, Groningen, The Netherlands; ' Unidad de \\ Posgrado, Facultad de Medicina, Universidad Nacional Autónoma de México, Mexico City, \\ Mexico; ${ }^{\mathrm{d}}$ Department of Internal Medicine, The American British Cowdray Medical Center, \\ Mexico City, Mexico; ' Laboratory of Neurochemistry and Behavior, Institute Born-Bunge, \\ University of Antwerp, Antwerp, Belgium
}

Keywords

Alzheimer · Anosognosia - Dementia · Decision-making capacity · Euthanasia · Suffering

\section{Abstract}

Background: Requests for physician-assisted death (PAD) in patients with cognitive impairment are complex and require careful consideration. Of particular difficulty is determination of whether the request is voluntary and well considered. Results: Euthanasia and physicianassisted suicide (PAS) are both legal in The Netherlands, Luxemburg, Colombia, and Canada. Euthanasia is legal in Belgium, while PAS is legal in Switzerland and Oregon, Washington, Montana, Vermont, and California (USA). Upon a PAD request, evaluation of the capacity to consent medical treatment is relevant for the decision-making process, while evaluation of testamentary capacity is appropriate before an advance euthanasia directive is written. Anosognosia assessment throughout the Alzheimer's disease continuum provides essential and relevant information regarding the voluntary and well-considered nature of the PAD request; meanwhile, early assessment of hypernosognosia or subjective cognitive decline assists in formulation of a clinical prognosis. Furthermore, the assessment of physical and psychological suffering should incorporate verbal and nonverbal cues as well as consideration of the psychosocial factors that might affect due care criteria. Conclusion: The clinical approach to a PAD request should consider the legal framework and the decision-making capacity, assess memory deficit awareness and the perception of suffering, and evaluate mental competency when considered pertinent. 
Mondragón et al.: Clinical Considerations in PAD for Probable AD

\section{Introduction}

\section{Alzheimer's Disease Continuum}

The research and clinical consensus suggest division of the cognitive decline continuum in Alzheimer's disease (AD) into the following 3 stages: preclinical, prodromal, and clinical (i.e., mild, moderate, and severe) [1]. Mild cognitive impairment (MCI) is the transitional cognitive state between normal aging and mild dementia [2]. Of particular interest is amnestic $\mathrm{MCI}$ (aMCI) due to its emphasis on memory loss. Lastly, AD is a progressive cerebral disease defined by a clinical component and a pathological component. Clinically AD involves anterograde memory impairment and deficits in one or several of the following cognitive domains: language, visuospatial ability, praxis, and executive functioning [3].

Traditionally, the clinical approach to the diagnosis of dementia consists of the following 2 phases: (1) recognition of dementia symptoms with a syndromic diagnosis, followed by (2) determination of its cause or etiology [4]. While an important percentage of MCI patients remain stable for years or even revert to normal, patients with $\mathrm{MCI}$, particularly aMCI, have a higher risk of progressing to $\mathrm{AD}$ [5]. The diagnostic criteria for aMCI are the following: (1) memory loss complaints (corroborated by an informant), (2) memory impairment for age and education, (3) preserved general cognitive function, (4) ability to perform daily life activities, and (5) absence of dementia [2, 5, 6]. Clinically, AD involves anterograde memory impairment and deficits in one or several cognitive domains. The National Institute on Aging (NIA) and the Alzheimer's Association (AA) revised criteria for AD propose criteria for allcause dementia or core clinical criteria for dementia and criteria for AD dementia [7]. The terminology proposed by the NIA-AA for classification of AD patients is: "probable AD dementia," "possible AD dementia," and "probable or possible AD dementia with evidence of the AD pathophysiological process" [7]. The first 2 designations are intended for all clinical settings, while the third designation is used for research purposes only [7]. For detailed clinical classification criteria, the reader is referred to the to the NIA-AA diagnostic criteria for preclinical stages of AD [1], for MCI [5], and for dementia [7].

\section{Awareness of Memory Deficits: Anosognosia and Hypernosognosia}

Anosognosia is unawareness or denial of a neurological deficit [8]. Impaired selfawareness alludes to a partial loss of knowledge; correspondingly, anosognosia involves a complete loss of knowledge of one's impaired neurological or neuropsychological functions [9]. Anosognosia incidence and prevalence have been reported to vary widely across dementia populations. Anosognosia for activities of daily living (ADL) deficits can be present from an early stage of AD dementia and it has a reported frequency between 20 and $80 \%$, and it varies greatly due to the use of diverse diagnostic methods, sampling bias (i.e., community vs. memory clinic samples), and the use of heterogeneous sample sizes [10]. Patients with mild or moderate AD have a reported anosognosia incidence between 21 and $38 \%$ and a prevalence between 24.2 and $71.0 \%$ [11-13]. Cross-cultural assessment of the differences in unawareness of memory deficits in a large community-based study has shown regional differences in the frequency of anosognosia (i.e., $81.2 \%$ in India, $72.0 \%$ in Latin America, and 63.5\% in China) [14].

Hypernosognosia is a condition of heightened awareness of memory changes that precede objective cognitive deficits [15]. Clinically heightened awareness of changes in cognition should be assessed to evaluate subjective cognitive decline (SCD). The Subjective Cognitive Decline Initiative (SCD-I) criteria are: (1) subjective decline in memory, rather than other domains of cognition; (2) onset within the last 5 years; (3) age at onset older than or equal to 60 years; (4) concerns associated with SCD; and (5) report of subjective inferior performance versus peers [16]. While hypernosognosia and SCD focus on the heightened perception of 
memory deficits, their clinical significance and prognostic value differ. Although SCD in preclinical AD is probably variable and expressed heterogeneously, it may represent the first manifestation of $\mathrm{AD}[16,17]$. SCD has been associated with progression to $\mathrm{MCI}$, with annual conversion rates of $18.6 \%$ for patients who fulfill SCD-I criteria, $5.6 \%$ for patients with selfreported cognitive complaints not fulfilling SCD-I criteria (i.e., hypernosognosia), and 4.9\% for cognitively intact individuals without memory complaints [18]. Although SCD alone is not a specific symptom of preclinical $\mathrm{AD}$, low cognitive awareness may represent a preceding form of anosognosia and could potentially serve as an AD preclinical indicator as it precedes structural brain changes and impaired cognitive tests scores [19].

Perception of Physical and Psychological Suffering in Physician-Assisted Death Requests

Voluntary active euthanasia and physician-assisted suicide (PAS) are both legal in The Netherlands, Luxemburg, Colombia, and Canada. While euthanasia is the only legal form of physician-assisted death (PAD) in Belgium, PAS is the only legal form of PAD in Switzerland and Oregon, Washington, Montana, Vermont, and California (USA). The legal outlook in relation to PAD in Latin America is contrasting. Although PAD has been decriminalized in Colombia for over 2 decades, it is rarely performed or reported; meanwhile, other countries like Mexico are in the process of reforming their policies regarding PAD. For a global perspective regarding the legal framework, we refer the reader to the online supplementary Appendix (for all online suppl. material, see www.karger.com/doi/10.1159/000500183).

Unbearable suffering is one of the due care criteria when assessing the request for PAD in Belgium and The Netherlands. Clinical determination of unbearable suffering in a patient with dementia who may no longer be able to communicate is a complex topic. The topic of what "unbearable suffering" is and what the ethical implications in PAD requests are is a current controversy that is being addressed. For a discussion about bioethical concepts and philosophical arguments regarding PAD in patients with dementia, the authors refer the reader to the work by de Beaufort and van de Vathorst [20] for insight into the concepts of voluntariness and suffering. For clinicians assessing the condition of unbearable suffering, this evaluation should be centered on the physical and psychological aspects of the patient's suffering.

\section{Objectives}

The primary aim of this article is to provide a clinical approach for clinical decision making regarding $\mathrm{PAD}$ for patients with $\mathrm{AD}$. In order to accomplish this objective, a reflection on the clinical approach for PAD will be presented. Three clinical aspects will be discussed: firstly, the clinical determination of loss of mental competence in the AD continuum; secondly, the clinical assessment of anosognosia and hypernosognosia; and, finally, the assessment of physical and psychological suffering. We contend that the physician addressing an end-of-life request must be aware of the legal status of the requested PAD option in his jurisdiction, and he or she must be able to determine the patient's mental competence; additionally, in order to make opportune end-of-life decisions, the physician needs to consider the patient's awareness of memory deficits and perception of physical or psychological suffering.

\section{Clinical Approach for PAD in AD Continuum}

\section{Clinical Determination of Loss of Mental Competence in Dementia}

In order for a request to be voluntary and well considered, the patient must be capable of making an informed decision. Dutch regional committees stipulate that the "(attending) physicians must be able to ascertain, or obtain confirmation that the patient is capable of 
informed consent" [21]. Furthermore, the committees state that patients with advanced dementia will rarely be capable of informed consent [21]. Although they are at times used interchangeably, the terms "capacity" and "competency" are related but distinct. Capacity may be defined as a threshold requirement for a person to make an autonomous decision [22]. While capacity refers to a clinical concept determined by a physician or health professional $[22,23]$, competency alludes to the ability of an individual to make decisions and is assessed by a legal professional $[22,24]$. However, the term capacity is currently utilized by the legal profession, and hence the term capacity is suitable for both clinical and legal application [22]. The authors refer the reader to the work by Moye et al. [22] for a historical and evolutionary perspective of the term capacity in legal and clinical practice.

Evaluation of treatment consent capacity is relevant to the decision-making process regarding a PAD request, while evaluation of testamentary capacity is appropriate if the patient desires to redact an advance euthanasia directive (AED). Clinical assessment of competency should include a detailed and comprehensive interview, a targeted neuropsychological evaluation, a functional ability assessment, and a review of the legal standards [25]. Optimally, the patient and the physician should have a professional but close relationship, one that can only be attained through personal interactions. The ideal assessment of testamentary capacity should include a general psychiatric evaluation, a clinical interview with observation of the patient's functional abilities, a set of neuropsychological tests, an evaluation of the patient's functional abilities, and consideration of the current legal framework [26]. Patients with certain stages of dementia are impaired in their capacity to consent to medical treatment; furthermore, as dementia progresses, so does consent impairment [27]. Capacity is task specific [23] and the following 8 major capacity domains are relevant to older adults with neuropsychiatric illness: (1) independent living, (2) financial management, (3) treatment consent, (4) testamentary capacity, (5) research consent, (6) sexual consent, (7) voting, and (8) driving [27]. While decision-making abilities vary across individuals, competent individuals must possess the ability to choose independently, understanding the important information relevant to their choice [28]. The nature of the request for PAD or AED must be completely voluntary, be carefully considered, and made repeatedly by the patient [29]. Patients seeking PAD must understand the diverse prognostic outcomes and experiences of patients with dementia [28].

The strategy for evaluation of the decision-making capacity can be simplified into the following 5 steps according to Moberg and Rick [25]: (1) clarification of the referral question and determination of the patient's mental competence; (2) planning, cultural assessment, and ethical considerations according to the topic; (3) assessment; (4) communication of the results; and (5) recommendation of any additional evaluations or interventions [25]. Standardized capacity assessment instruments supplement and should not supplant clinical judgment regarding capacity [27]. Evaluation of competency in elderly patients requires a dynamic approach which includes the use of multiple standardized measures in order to adequately assess the skills and attitudes necessary for daily function [25]. Although no standardized instrument assessing capacity is considered the gold standard, various instruments are available to measure the capacity to consent treatment (e.g., MacArthur Competence Assessment Tool and Capacity to Consent to Treatment Instrument), testamentary capacity (e.g., Testamentary Capacity Assessment Tool and Testamentary Capacity Instrument), financial decision making (e.g., Financial Capacity Instrument and Measure of Awareness of Financial Skills), and the capacity to live independently (e.g., Everyday Cognition Scale, Activities of Daily Living International Scale, Functional Activities Questionnaire, and Disability Assessment in Dementia) in patients with cognitive impairment [25, 30]. Although these instruments are valuable in assessment of the decision-making capacity, they are burdensome and time consuming [26]. However, these instruments provide evidence regarding the 
decision-making capacity of the patient with dementia requesting a PAD or drafting an AED; concurrently, they serve as screening tools for candidates for a more extensive evaluation.

When evaluating a patient's request for PAD or AED, Dutch regional committees look at possible inhibiting factors such as depression or cognitive disorders, making a distinction between clinical depression and depressive symptoms [29]. If a differential diagnosis cannot be made by the attending physician, assessment by an independent psychiatrist may help to confirm that the request is voluntary and carefully considered; it is also necessary to determine whether the patient is suffering from depression and is capable of informed consent [29]. The regional committee advises that a multidisciplinary team should manage PAD requests from patients with dementia, and the team should preferably include a psychiatrist or a geriatrician [31]. Patients considered to lack mental competence have been associated with having their request for PAD denied [32]. Almost all cases involving PAD in dementia in The Netherlands have involved patients at the early stages of the disease [20]. The lower number of PAD cases involving advanced dementia might be a result of the difficulty to comply with the due care criteria as patients in advanced stages are no longer considered competent. Most requests for PAD are from patients with cancer (72\%), followed by patients with another physical disease (19\%), those with dementia (4\%), those who are tired of living (3\%), and those with a psychiatric disease (2\%) [33]. A patient's written declaration of intention (i.e., AED) is the alternative to a mentally competent request given orally from an advanced dementia patient and, even though these are difficult cases, the regional committees state that PAD compliance cannot be excluded [31]. Given that the aim of this work is to provide the legal framework and clinical approach necessary to adequately assist patients with preclinical or clinical dementia concerning PAD and AED and help the physician's decision-making process when evaluating and/or executing a PAD or an AED request, we refer the reader to the work by Legemaate and Bolt [31], where the reader will find a review of the recent legal developments regarding the extensive legal debate about AED compliance over the last 5 years. Interestingly, in cases involving an AED for patients with advanced dementia, the attending physicians tend to disregard the directive and base their decisions on the current situation, thus basing their decision on the moral concept of beneficence rather than the patient's autonomy [34]. For further reading regarding the controversial status of PAD for patients with dementia in Belgium, the authors refer the reader to the work by Cohen-Almagor [35], where the reader will find contrasting arguments about this topic.

Supporters of legalization of PAD for dementia in the USA argue that authorities should protect individual autonomy and self-determination by allowing people the freedom to choose an earlier death over the suffering and indignities of life with dementia [28]. However, all medical decisions, especially choices regarding PAD, should be competent and informed [28]. The clinical approach regarding the concept of mental capacity to request PAD varies depending on the legal status of the different end-of-life alternatives. Physicians must be attentive to the ongoing changes in the law and cases in their particular jurisdictions regarding PAD. Extensive literature regarding the determination of consent to treatment and testamentary capacity is a prominent topic of discussion in the fields of forensic psychiatry and medical law. For further reading about strategies regarding the determination of mental competence in patients with dementia under English common law, the authors refer the reader to the work by Stewart et al. [36] and to the work by Weinberger et al. [37] for more information about mental health assessment in these jurisdictions. For a comprehensive review of testamentary capacity assessment with a special emphasis on patients with dementia, the authors recommend the work of Voskou et al. [26]. Overall, during the evaluation of mental competence to consent to medical treatment (i.e., treatment consent capacity), the physician must ascertain that the decision is voluntary, free, well informed, consistent over time, and, optimally, quantifiable through a psychometric evaluation. 


\section{Clinical Assessment of Anosognosia and Hypernosognosia}

Clinical data associate anosognosia with different dementias; in fact, clinical-pathological studies have suggested that dementia-related pathologies account for most cases of late-life anosognosia [38]. In a nondemented-at-baseline large longitudinal study, the temporal course of unawareness of memory impairment occurred 2.6 years before dementia onset [39], with an incidence of mild and moderate dementia of 37.0 and $42.3 \%$, respectively [12]. Anosognosia in $\mathrm{AD}$ most often refers to deficits in ADL and behavioral changes rather than awareness of illness or deficits in neuropsychological evaluations [10]. Anosognosia is more frequent as dementia progresses, present in $10 \%$ of very mild dementia cases and $57 \%$ of patients with severe dementia, making the severity of dementia the main determinant of anosognosia [10]. The association between cognition and awareness over time is not clear, as some patients remain stable or even improve despite cognitive decline [40]. The severity of dementia has also been associated with a discriminative factor between persistent and nonpersistent anosognosia [12], which could explain the variability in remission rates. A remission rate of $20 \%$ during the 12-month follow-up period has been reported [12], while an $11 \%$ remission rate was reported in another study with a variable follow-up period between 1 and 4 years [13].

Until now, there is no official method to diagnose anosognosia in AD, yet neuropsychiatric assessment by an experienced clinician complemented with additional information provided by an informant is considered the gold standard [10]. In research, the following 3 different assessment methods for awareness of a memory deficit exist: (1) measurement instruments that incorporate a discrepancy score between the patient and an informant; (2) measurement instruments based on a self-accuracy discrepancy score, in which the patient prospectively attempts to predict his or her performance on a neuropsychological test; and (3) measurement based on the examiner's judgment. Although many awareness screening instruments are available to assess anosognosia in $\mathrm{AD}$, the Anosognosia Questionnaire-Dementia (AQ-D) is most widely used [10]. Classification of anosognosia in a review of 64 studies in 2014 was assessed using 41 different methods, which reflects the lack of conceptual clarity and methodological consistency surrounding this condition [41]. A gradual increase in the assessment battery for anosognosia is observed by the number of measures available in the last 4 decades (i.e., 6 new methods from 1978 to 1989, adding 21 new methods from 2002 to 2013) [41].

In the field of legal and forensic psychiatry, a nascent topic has emerged - in essence, research into the associations between awareness of memory deficits and clinical mental competence. While neuropsychological tests used for the assessment of executive functions are not suitable for investigating mental competence, recently an instrument was designed to measure deficits of insight and judgment in patients with dementia [42]. In a current effort to address the need for psychometric instruments that evaluate awareness and judgment, the Structured Interview for Insight and Judgment in Dementia was developed and validated in a memory clinic setting [43]. However, this instrument needs to be validated across different populations and settings (i.e., memory clinic and community-dwelling), including longitudinal follow-up.

Patients with SCD have a 360\% increased risk of MCI progression compared to people without cognitive complaints, while patients with hypernosognosia have a $32 \%$ increased risk of progression to MCI compared to people without cognitive complaints [18]. In cognitively unimpaired normal adults hypernosognosia is associated with positive $\beta$-amyloid positron emission tomography (i.e. Pittsburg compound B), while in MCI patients anosognosia is associated with in vivo $\beta$-amyloid pathology [15]. The physician must remain cognizant of the psychological burden that a recent dementia diagnosis entails for a patient. To address this concern, the assessment of anxiety and depressive symptoms must be included in the evaluation of patients with cognitive complaints and suspected hypernosognosia in order to adequately make a differential diagnosis with SCD. This evaluation not only assists 
in the differential diagnosis of cognitive decline but it also impacts the evaluation of mental competence in the AD continuum [44].

The physician evaluating a PAD request must take into consideration the level of awareness the patient has about his or her memory deficits (i.e., both anosognosia and hypernosognosia) as these might be influencing his/her likelihood to request euthanasia or not. Further research regarding the incidence of awareness of memory deficits in patients requesting PAD is needed to evaluate the role that these clinical entities, as well as other neuropsychological conditions (e.g., apathy and anxiety), play in the end-of-life decisionmaking process. These behavioral variables need to be further studied as we currently do not know if these behavioral conditions interfere with the decision-making process and, if so, what clinical steps must be taken upon the request of a PAD by a patient with an altered level of awareness of memory deficits.

\section{Clinical Assessment of Suffering in End-of-Life Requests}

The Dutch due care criteria for PAD state that the attending physician has come to the conviction that the suffering of the patient is unbearable and without a prospect of improvement and that there are no more reasonable alternatives to relieve the patient's suffering. Suffering is a very personal experience that encompasses physical, psychological, and social factors. While the due care criteria allow for a clinical and a personal discretionary framework, the clinician is granted the power to subjectively assess the patient's suffering. Each clinician is bestowed with the privilege and authority to assess the patient's well-being, which includes the competency to evaluate the patient's level of suffering.

Both physical and psychological suffering must be considered when the clinician is evaluating unbearable suffering. Nonverbal communication becomes of paramount importance for the evaluating physician, as the physician must be able to interpret the body language and limited verbal responses from the patient [31]. In advanced stages of dementia, the physician must indirectly infer the patient's suffering from behavioral cues related to a loss of brain function such as loss of control, anxiety, mood swings, and helplessness; additionally, the patient may also suffer from behavioral and psychological symptoms of dementia and neuropsychiatric symptoms, such as self-harm, stereotypic behavior, and hallucinations, among others. To this regard, the Royal Dutch Medical Association (RMDA) proposes that the physician evaluating a PAD request should consider the psychosocial or existential suffering as part of the medical domain when evaluating unbearable suffering [31]. In particular, vulnerability represented in loss of function, loneliness, and loss of autonomy should be considered during the PAD decision-making process. Overall, the attending physician must consider the entire patient's well-being, taking into consideration the physical, psychological, and social factors that influence his or her current health status.

\section{Conclusion}

The aim of this review was to provide a clinical approach for clinical decision making regarding PAD for patients with $\mathrm{AD}$. Requests for PAD in patients with dementia are complex and require careful consideration. Of particular difficulty is the determination of whether the request is voluntary and well considered. Capacity to consent to medical treatment has a clinical, an ethical, and a legal domain. A physician evaluating a PAD request must know the legal framework of his or her jurisdiction and should consider the ethical implications, as well as the clinical circumstances, that surround an end-of-life request. The determination of decisional competence and awareness of his memory deficits is of considerable importance when assessing if the patient's request meets the due care criteria of a voluntary and well-considered end-of-life request. 
In addition to considering the stage in the cognitive decline continuum, the physician attending a PAD request from an AD patient must assess the patient's awareness of memory deficits. Assessment for hypernosognosia or SCD early in the disease course assists in the establishment of the prognosis. Assessment for anosognosia throughout the AD continuum provides essential and relevant information regarding the voluntary and well-considered nature of the PAD request. Overall, the clinical approach to addressing a PAD request must carefully consider the legal framework of the patient's jurisdiction, perform a careful evaluation of the decision-making capacity to consent to medical treatment, and assess the awareness of memory deficits and suffering as a supplement to decisional competence evaluation when considered pertinent. The screening tools available for the decision-making capacities and awareness of memory deficits provide supporting evidence in the clinical evaluation of a patient with dementia requesting a PAD; however, these instruments do not replace clinical assessment and if uncertainty about the decision-making status arises the conclusion is that the patient requires a more extensive evaluation.

An AED request marks the final chapter of a patient's life. Considering that the decision to request an AED is primarily the patient's but the clinical assessment (i.e., assessment of mental competence, influencing factors, and contributing conditions) and execution of the PAD is the physician's responsibility, a good patient-physician relationship is of paramount importance in the PAD shared decision process [32, 45]. A strong patient-physician relationship is substantiated on the principle of communication. An advance directive is only possible if the patient understands his or her prognosis and his or her end-of-life wishes are communicated to his or her family and his or her attending physician.

\section{Acknowledgement}

The authors would like to acknowledge the important endeavor that the 5 Dutch regional euthanasia review committees, Regionale Toetsingscommissies Euthanasie, have done over the years - in particular, their effort to provide transparency in their evaluation process by publishing annual reports and selected cases on their website. Without these resources, this work would not have been possible.

\section{Statement of Ethics}

Due to the nature of this work, it did not need approval from our institutions' review boards.

\section{Disclosure Statement}

None of the authors report conflicts of interests.

\section{Funding Sources}

This work was supported by the CONACyT (Consejo Nacional de Ciencia y Tecnología) under grant No. 440591. This research did not receive any specific grant from funding agencies in the commercial or not-for-profit sector. 
Mondragón et al.: Clinical Considerations in PAD for Probable AD

\section{References}

1 Sperling RA, Aisen PS, Beckett LA, Bennett DA, Craft S, Fagan AM, et al. Toward defining the preclinical stages of Alzheimer's disease: recommendations from the National Institute on Aging-Alzheimer's Association workgroups on diagnostic guidelines for Alzheimer's disease. Alzheimers Dement. 2011 May;7(3):280-92.

2 Petersen RC, Doody R, Kurz A, Mohs RC, Morris JC, Rabins PV, et al. Current concepts in mild cognitive impairment. Arch Neurol. 2001 Dec;58(12):1985-92.

3 Boughey JG, Graff-Radford NR. Alzheimer's disease. In: Schapira A, ed. Neurology and clinical neuroscience. 1st ed. Philadelphia: Mosby Elsevier; 2007. p. 846-58.

4 Dubois B, Feldman HH, Jacova C, Dekosky ST, Barberger-Gateau P, Cummings J, et al. Research criteria for the diagnosis of Alzheimer's disease: revising the NINCDS-ADRDA criteria. Lancet Neurol. 2007 Aug;6(8):734-46.

5 Albert MS, DeKosky ST, Dickson D, Dubois B, Feldman HH, Fox NC, et al. The diagnosis of mild cognitive impairment due to Alzheimer's disease: recommendations from the National Institute on Aging-Alzheimer's Association workgroups on diagnostic guidelines for Alzheimer's disease. Alzheimers Dement. 2011 May; 7(3):270-9.

6 Winblad B, Palmer K, Kivipelto M, Jelic V, Fratiglioni L, Wahlund LO, et al. Mild cognitive impairment-beyond controversies, towards a consensus: report of the International Working Group on Mild Cognitive Impairment. J Intern Med. 2004 Sep;256(3):240-6.

7 McKhann GM, Knopman DS, Chertkow H, Hyman BT, Jack CR Jr, Kawas CH, et al. The diagnosis of dementia due to Alzheimer's disease: recommendations from the National Institute on Aging-Alzheimer's Association workgroups on diagnostic guidelines for Alzheimer's disease. Alzheimers Dement. 2011 May;7 (3):263-9.

8 Langer KG, Levine DN. Babinski, J. (1914). Contribution to the study of the mental disorders in hemiplegia of organic cerebral origin (anosognosia). Translated by K.G. Langer \& D.N. Levine. Translated from the original Contribution à l’Étude des Troubles Mentaux dans l'Hémiplégie Organique Cérébrale (Anosognosie). Cortex. 2014 Dec;61(61):5-8.

9 Prigatano GP. Anosognosia and patterns of impaired self-awareness observed in clinical practice. Cortex. 2014 Dec;61:81-92.

10 Starkstein SE. Anosognosia in Alzheimer's disease: diagnosis, frequency, mechanism and clinical correlates. Cortex. 2014 Dec;61:64-73.

11 Castrillo Sanz A, Andrés Calvo M, Repiso Gento I, Izquierdo Delgado E, Gutierrez Ríos R, Rodríguez Herrero R, et al. Anosognosia in Alzheimer disease: prevalence, associated factors, and influence on disease progression. Neurologia. 2016 Jun;31(5):296-304.

12 Turró-Garriga O, Garre-Olmo J, Calvó-Perxas L, Reñé-Ramírez R, Gascón-Bayarri J, Conde-Sala JL. Course and Determinants of Anosognosia in Alzheimer's Disease: A 12-Month Follow-up. J Alzheimers Dis. 2016;51(2): 357-66.

13 Starkstein SE, Brockman S, Bruce D, Petracca G. Anosognosia is a significant predictor of apathy in Alzheimer's disease. J Neuropsychiatry Clin Neurosci. 2010;22(4):378-83.

14 Mograbi DC, Ferri CP, Sosa AL, Stewart R, Laks J, Brown R, et al. Unawareness of memory impairment in dementia: a population-based study. Int Psychogeriatr. 2012 Jun;24(6):931-9.

15 Vannini P, Amariglio R, Hanseeuw B, Johnson KA, McLaren DG, Chhatwal J, et al. Memory self-awareness in the preclinical and prodromal stages of Alzheimer's disease. Neuropsychologia. 2017 May; 99:343-9.

16 Jessen F, Amariglio RE, van Boxtel M, Breteler M, Ceccaldi M, Chételat G, et al.; Subjective Cognitive Decline Initiative (SCD-I) Working Group. A conceptual framework for research on subjective cognitive decline in preclinical Alzheimer's disease. Alzheimers Dement. 2014 Nov;10(6):844-52.

17 Molinuevo JL, Rabin LA, Amariglio R, Buckley R, Dubois B, Ellis KA, et al.; Subjective Cognitive Decline Initiative (SCD-I) Working Group. Implementation of subjective cognitive decline criteria in research studies. Alzheimers Dement. 2017 Mar;13(3):296-311.

18 Fernández-Blázquez MA, Ávila-Villanueva M, Maestú F, Medina M. Specific Features of Subjective Cognitive Decline Predict Faster Conversion to Mild Cognitive Impairment. J Alzheimers Dis. 2016 Mar;52(1):271-81.

19 Cacciamani F, Tandetnik C, Gagliardi G, Bertin H, Habert MO, Hampel H, et al.; INSIGHT-PreAD study group. Low Cognitive Awareness, but Not Complaint, is a Good Marker of Preclinical Alzheimer's Disease. J Alzheimers Dis. 2017;59(2):753-62.

20 de Beaufort ID, van de Vathorst S. Dementia and assisted suicide and euthanasia. J Neurol. 2016 Jul;263(7): 1463-7.

21 RTE Regional Euthanasia Review Committees [Internet]. RTE 2006 Annual Report. Available from: https:// english.euthanasiecommissie.nl/the-committees/documents/publications/annual-reports/2006/annualreports/annual-reports.

22 Moye J, Marson DC, Edelstein B. Assessment of capacity in an aging society. Am Psychol. 2013 Apr;68(3):15871.

23 Jacoby R, Steer P. How to assess capacity to make a will. BMJ. 2007 Jul;335(7611):155-7.

24 Moberg PJ, Kniele K. Evaluation of competency: ethical considerations for neuropsychologists. Appl Neuropsychol. 2006;13(2):101-14.

25 Moberg PJ, Rick JH. Decision-making capacity and competency in the elderly: a clinical and neuropsychological perspective. NeuroRehabilitation. 2008;23(5):403-13. 
Mondragón et al.: Clinical Considerations in PAD for Probable AD

Voskou P, Douzenis A, Economou A, Papageorgiou SG. Testamentary capacity assessment: legal, medical, and neuropsychological issues. J Geriatr Psychiatry Neurol. 2018; 31(1):3-12.

27 Moye J, Marson DC. Assessment of decision-making capacity in older adults: an emerging area of practice and research. J Gerontol B Psychol Sci Soc Sci. 2007 Jan;62(1):3-P11.

28 Dresser R. On Legalizing Physician-Assisted Death for Dementia. Hastings Cent Rep. 2017 Jul;47(4):5-6.

29 RTE Regional Euthanasia Review Committees [Internet]. RTE 2002 Annual Report. Available from: https:// english.euthanasiecommissie.nl/the-committees/documents/publications/annual-reports/2002/annualreports/annual-reports.

30 Lindbergh CA, Dishman RK, Miller LS. Functional Disability in Mild Cognitive Impairment: A Systematic Review and Meta-Analysis. Neuropsychol Rev. 2016 Jun;26(2):129-59.

31 Legemaate J, Bolt I. The Dutch Euthanasia Act: recent legal developments. Eur J Health Law. 2013 Dec;20(5): 451-69.

32 Snijdewind MC, Willems DL, Deliens L, Onwuteaka-Philipsen BD, Chambaere K. A Study of the First Year of the End-of-Life Clinic for Physician-Assisted Dying in the Netherlands. JAMA Intern Med. 2015 Oct; 175(10):163340.

33 Bolt EE, Snijdewind MC, Willems DL, van der Heide A, Onwuteaka-Philipsen BD. Can physicians conceive of performing euthanasia in case of psychiatric disease, dementia or being tired of living? J Med Ethics. 2015 Aug; 41(8):592-8.

34 Hertogh CM, de Boer ME, Dröes RM, Eefsting JA. Would we rather lose our life than lose our self? Lessons from the Dutch debate on euthanasia for patients with dementia. Am J Bioeth. 2007 Apr;7(4):48-56.

35 Cohen-Almagor R. First Do No Harm: Euthanasia of Patients with Dementia in Belgium. J Med Philos. 2016 Feb; 41(1):74-89.

36 Stewart C, Peisah C, Draper B. A test for mental capacity to request assisted suicide. J Med Ethics. 2011 Jan; 37(1):34-9.

37 Weinberger LE, Sreenivasan S, Garrick T. End-of-life mental health assessments for older aged, medically ill persons with expressed desire to die. J Am Acad Psychiatry Law. 2014;42(3):350-61.

38 Wilson RS, Sytsma J, Barnes LL, Boyle PA. Anosognosia in Dementia. Curr Neurol Neurosci Rep. 2016 Sep; 16(9):77.

39 Wilson RS, Boyle PA, Yu L, Barnes LL, Sytsma J, Buchman AS, et al. Temporal course and pathologic basis of unawareness of memory loss in dementia. Neurology. 2015 Sep;85(11):984-91.

40 Vogel A, Waldorff FB, Waldemar G. Longitudinal changes in awareness over 36 months in patients with mild Alzheimer's disease. Int Psychogeriatr. 2015 Jan;27(1):95-102.

41 Nurmi Laihosalo ME, Jehkonen M. Assessing anosognosias after stroke: a review of the methods used and developed over the past 35 years. Cortex. 2014 Dec;61:43-63.

42 Gambina G, Bonazzi A, Valbusa V, Condoleo M, Bortolami O, Broggio E, et al. Awareness of cognitive deficits and clinical competence in mild to moderate Alzheimer's disease: their relevance in clinical practice. Neurol Sci. 2014 Mar;35(3):385-90.

43 Parrao T, Brockman S, Bucks RS, Bruce DG, Davis WA, Hatch KK, et al. The Structured Interview for Insight and Judgment in Dementia: development and validation of a new instrument to assess awareness in patients with dementia. Alzheimers Dement (Amst). 2016 Dec;7:24-32.

44 Bertrand E, van Duinkerken E, Landeira-Fernandez J, Dourado MC, Santos RL, Laks J, et al. Behavioral and psychological symptoms impact clinical competence in Alzheime's disease. Front Aging Neurosci. 2017 Jun;9: 182.

45 Dees MK, Vernooij-Dassen MJ, Dekkers WJ, Elwyn G, Vissers KC, van Weel C. Perspectives of decision-making in requests for euthanasia: a qualitative research among patients, relatives and treating physicians in the Netherlands. Palliat Med. 2013 Jan;27(1):27-37. 